\title{
The effects of flow on feeding of three gorgonians from southern Taiwan
}

\author{
Chang-Feng Dai and Ming-Chao Lin \\ Institute of Oceanography, National Taiwan University, Taipei, Taiwan, ROC
}

(Received 30 January 1992; revision received 7 June 1993; accepted 11 June 1993)

\begin{abstract}
The feeding performances of three gorgonians, Subergorgia suberosa, Melithaea ochracea, Acanthogorgia vegae, in different flow regimes were studied. The three gorgonians expanded their polyps and fed in varying ranges of flow velocities. Differences in the feeding range are possibly related to polyp morphologies. S. suberosa, which has tall polyps and encounters higher drag, is more easily deformed in currents; it feeds in a narrow range of flow velocities $\left(7-9 \mathrm{~cm} \cdot \mathrm{s}^{-1}\right)$. M. achracea, which has short polyps and encounters lower drag, is less readily deformed in currents; it feeds in a wider range of flow velocities $\left(4-40 \mathrm{~cm} \cdot \mathrm{s}^{-1}\right)$. Polyp heights of $A$. vegae are intermediate and this coral feeds in currents of $2-22 \mathrm{~cm} \cdot \mathrm{s}^{-1}$. The upper limits on the flow ranges are considered to be determined by the balance between the energy gained from feeding and the cost of keeping the polyps expanded. Optimal feeding rates of the three gorgonians were found at moderate flow velocities. Feeding rates increased initially with flow velocity, reached a peak value at $8 \mathrm{~cm} \cdot \mathrm{s}^{-1}$. then decreased with increasing flow velocities. Both the colony feeding effectiveness and the polyp feeding effectiveness at $8 \mathrm{~cm} \cdot \mathrm{s}^{-1}$ are ranked: $S$. suberosa $>A$. vegue $>M$. ochracea.
\end{abstract}

Key words: Gorgonacea; Suspension feeding; Water flow

\section{INTRODUCTION}

Feeding is an essential activity for most animals because it provides the basic energy for sustaining lifc. Passivc suspension feeders such as octocorals depend on exogenous current for food delivery and waste disposal; thus their distributions are often related to flow velocity of the environment (Jørgenson, 1955; Riedl, 1971; Koehl, 1977; Muzik \& Wainwright, 1977; Sebens, 1984). Current-induced drag forces can dislodge organisms (Riedl, 1971; Wainwright et al., 1976) and interrupt their particle capture activities (Patterson, 1984; Best, 1988) while low flow velocities may result in food deficiency (Harvell \& LaBarbera, 1985). The conflicting demands of maximizing feeding efficiency and minimizing drag forces often exist in passive suspension feeders. Habitats where flow is most often within the optimal range offer the greatest advantage of feeding and survival for marine sessile organisms. As a consequence, marine sessile organisms often live and feed in a particular range of current velocities.

Functional constraints arising from the conflicting demands of maximizing feeding

Correspondence address: C.-F. Dai, Institute of Oceanography, National Taiwan University, Taipei 10764, Taiwan, ROC. 
and minimizing drag are often characterized by certain morphological features of sessile organisms. The effect of flow velocity on feeding abilities has been the focus of several investigations (Best, 1988; Okamura, 1990; Patterson, 1991). But the combined influences of flow velocities and morphological characters on feeding abilities has received hitle attention.

Gorgonians (Anthozoa: Gorgonacea) are one of the major benthic organism of tropical coral reefs. They display a variety of colony morphologies and occupy various habitats on reefs (Bayer, 1981). Colony morphology and orientations of gorgonians are related to current regimes (Wainwright \& Dillon, 1969; Grigg, 1971; Leversee. 1976). Colonies occurring in uni- or bidirectional currents are often planar and oriented perpendicular to the prevailing current direction. Several studies have demonstrated the effects of flow velocities on feeding abilities of gorgonians (Leversee, 1976; Lasker et al., 1983; Sponaugle \& LaBarbera, 1991). Lasker (1981) compared the feeding abilities of three Caribbean gorgonians in experiments conducted in feeding chambers or in flow tanks under relatively low current speeds $\left(3.5\right.$ and $\left.7.3 \mathrm{~cm} \cdot \mathrm{s}^{-1}\right)$. Sponaugle \& LaBarbera (1991) studied the feeding rates of two Caribbean gorgonians with similar morphologies in a range of current velocities. However, the relative feeding abilities of morphologically different species in various flow velocities have rarely been studied.

The purpose of this study is twofold: (1) to examine the effects of flow velocities on the shape and feeding performance of three gorgonians with different colony and polyp morphologies, and (2) to utilize laboratory results to account for the distribution pattern of the three species on reefs. Three gorgonian species, Subergorgia suberosa (Pallas, 1776). Acanthogorgia vegae Aurivilus, 1931, and Melithaea ochracea Linnaeus, 1758. were selected for this study. Colonies of $S$ suberosa are often planar or bushy with the plane perpendicular to the current direction. Branches are separated by as much as $3 \mathrm{~cm}$. They often grow on the lower part of reef slopes or on boulders scattered over a sandy bottom. A. vegae colonies are flabellated and usually grow on the lateral side of blocks or reef fronts. Colonies of $M$. ochracea are multiplanar and often exist on upper part of reef fronts or boulders where the current is relatively strong. The plane of the fan is oriented perpendicular to the direction of current. All the three species are widely distributed throughout the fringing reefs of southern Taiwan (Chen \& Chang, 1991 ) and on Pacific coral reefs (Muzik \& Wainwright, 1977).

\section{Materials AND METHODS}

Colonies of the three species, each about $15 \mathrm{~cm}$ high, were collected from Nanwan Bay, southern Taiwan $120^{\circ} 44^{\prime} \mathrm{E}, 21^{\circ} 57^{\prime} \mathrm{N}$ ). Specimens were collected on the same reef but from different depths and microhabitats. Species identifications followed Chen \& Chang (1991) and related references (Muzik \& Wainwright, 1977; Zou \& Scott, 1980 ; Bayer, 1981$)$

Colonies collected from the field were transferred to a tank and allowed 2 weeks of 
acclimation before the experiment. The acclimation tank was furnished with two current generators which create consistent flow and the coral colonies were fed with Artemia nauplii.

Morphometric studies of the gorgonians were conducted in lab by using a digitizer (Lab Visions LV-1) associated with a personal computer. Colonies were immersed in a sea-water tank and their projected areas, number of branches, and total lengths of branches were measured. The total number of polyps was estimated by counting polyps in 10 randomly selected $1 \mathrm{~cm}$ segments from a colony. Polyp length and oral disk diameter were measured under a stereomicroscope when the polyps were fully expanded.

A recirculating flow tank of $75-1$ capacity $(150 \mathrm{~cm}$ long, $60 \mathrm{~cm}$ wide and $20 \mathrm{~cm}$ high) was made with reference to Leversee (1976). The tank was filled with $69 \mathrm{l}$ filtered seawater before experiment. A laboratory stirrer (Her-Cheng SC-VS35W) with a propeller (14 cm in diameter) was used to generate water flow. The flow velocity was regulated by a solid state motor control and measured by an electromagnetic current meter (Kenek VM-401H). The water temperature was maintained at $24^{\circ} \mathrm{C}$.

When flow velocity and water temperature were steady, a coral colony starved for at least $24 \mathrm{~h}$ was transferred into the tank and oriented perpendicular to the flow direction. The coral colony was allowed $3 \mathrm{~h}$ for further acclimation in such steady current regime. The range of flow velocities in which a coral colony expands its polyps

TABLE I

Morphometric data (mean $\pm 1 \mathrm{SD}$ ) of colony A and B of the three gorgonians (colony height $=15 \mathrm{~cm}$ ). Polyps are measured in fully expanded condition.

\begin{tabular}{lccc}
\hline \multicolumn{3}{c}{ Colony A } & \\
\hline & $\begin{array}{c}\text { Subergorgia } \\
\text { suberosa }\end{array}$ & $\begin{array}{c}\text { Acanthogorgia } \\
\text { vegae }\end{array}$ & $\begin{array}{c}\text { Melithaea } \\
\text { ochracea }\end{array}$ \\
\hline Total number of branches & 8 & 63 & 134 \\
Total length of branches $(\mathrm{cm})$ & 57.5 & 231.4 & 476.2 \\
Projected colony area $\left(\mathrm{cm}^{2}\right)$ & 56.3 & 92.3 & 167.3 \\
Total number of polyps & $1127 \pm 63$ & $4628 \pm 440$ & $18501 \pm 1192$ \\
Polyp density (polys $\left.\cdot \mathrm{cm}^{-2}\right)$ & 20.0 & 50.1 & 110.6 \\
Polyp height $(\mathrm{mm})$ & $5.32 \pm 0.26$ & $3.02 \pm 0.25$ & $0.96 \pm 0.18$ \\
Polyp diameter $(\mathrm{mm})$ & $5.12 \pm 0.24$ & $2.96 \pm 0.18$ & $0.95 \pm 0.15$ \\
\hline
\end{tabular}

\section{Colony B}

Total number of branches

Total length of branches $(\mathrm{cm})$

Projected colony area $\left(\mathrm{cm}^{2}\right)$

Total number of polyps

Polyp density (polys $\cdot \mathrm{cm}^{-2}$ )

Polyp height (mm)

Polyp diameter (mm)

11
67.7
65.8
$1354 \pm 74$
20.6
$5.19 \pm 0.31$
$5.17 \pm 0.22$

84

264.5

107.4

$4973 \pm 555$

46.3

$3.07 \pm 0.31$

$3.01 \pm 0.16$
152

496.6

173.9

$19814 \pm 1242$

113.9

$0.95 \pm 0.20$

$0.95 \pm 0.12$ 
was determined by treating each colony to a particular flow velocity for $3 \mathrm{~h}$. Each colony was tested in a range 0 to $40 \mathrm{~cm} \cdot \mathrm{s}^{-1}$ of flow velocities and the sequence was randomly assigned to the colony.

Feeding experiments were conducted in the range of flow velocities in which the coral expanded its polyps. Living Artemia nauplii were harvested from culture $24 \mathrm{~h}$ after hatching. 1400 Artemia nauplii were counted by naked eye using a $10 \mathrm{ml}$ pipette, diluted to 11 , and poured evenly into the flow tank. During the following $6 \mathrm{~h}$, the number of Artemia remaining in the tank was counted at 1 -h interval. The number of Artemia was determined by taking five 1-I samples using a 1-l beaker. Samples were poured through a plankton net $(200 \mu \mathrm{m})$ and the Artemia were counted on the netting. The Artemia were returned to the tank along with the filtered seawater after counting. Two colonies were tested for each species. Feeding experiments were made $48 \mathrm{~h}$ apart to allow complete clearing of Artemia from the polyp guts.

Feeding rates of the three gorgonians were normalized by number of polyps or surface area to compare their feeding effectiveness. Two normalization procedures were laken following Hunter (1989): (1) colony feeding effectiveness, a measure of feeding rate per unit area, and (2) polyp feeding effectiveness, a measure of feeding rate per 100 polyps. Because feeding rates during the first hour were most noticeable, these were used to represent colony feeding abilities.

TABLE II

Residual concentration ( 6 -h period of feeding experiment for Subergorgia suberosa. Initial concentration was 20 shrimps $\cdot 1^{-1}$.

\begin{tabular}{|c|c|c|c|c|c|c|}
\hline \multicolumn{7}{|c|}{ Colony A } \\
\hline \multirow{2}{*}{$\begin{array}{l}\text { Flow velocity } \\
\qquad\left(\mathrm{cm} \cdot \mathrm{s}^{\cdots 1}\right)\end{array}$} & \multicolumn{6}{|c|}{ Time (h) } \\
\hline & 1 & 2 & 3 & 4 & 5 & 6 \\
\hline 5 & $19.8 \pm 2.9$ & $20.2+1.2$ & $19.4 \pm 1.9$ & $19.8 \pm 1.8$ & $20.4+2.2$ & - \\
\hline 6 & $20.4 \pm 2.0$ & $20.4 \pm 2.7$ & $19.4+2.2$ & $19.2 \pm 1.5$ & $19.0 \pm 2.8$ & $19.2+0.8$ \\
\hline 7 & $16.8 \pm 1.2$ & $16.6+1.5$ & $16.6+1.2$ & $16.4 \pm 1.4$ & $16.8+1.6$ & $16.8+1.8$ \\
\hline 8 & $8.0 \pm 1.9$ & $7.8+1.5$ & $6.4+1.0$ & $6.2 \pm 1.7$ & $5.6 \pm 1.5$ & $5.0 \pm 1.9$ \\
\hline 9 & $16.6 \pm 1.0$ & $15.4+2.2$ & $14.8 \pm 1.7$ & $14.4 \pm 2.3$ & $13.8 \pm 2.0$ & $13.0 \pm 2.6$ \\
\hline 10 & $19.8 \pm 1.5$ & $19.8+1.3$ & $19.5+2.1$ & $20.8 \pm 0.8$ & - & - \\
\hline \multicolumn{7}{|c|}{ Colony B } \\
\hline 6 & $19.8 \pm 3.8$ & $19.6+2.6$ & $19.8+2.2$ & $19.2 \pm 2.6$ & $20.2 \pm 2.2$ & $20.0 \pm 2.8$ \\
\hline 7 & $14.6 \pm 2.6$ & $11.8 \pm 1.4$ & $10.0 \pm 2.0$ & $9.8 \pm 1.4$ & $9.2 \pm 3.0$ & $8.8 \pm 2.2$ \\
\hline 8 & $7.0 \pm 3.2$ & $5.6 \pm 1.0$ & $5.0 \pm 2.0$ & $4.4 \pm 1.8$ & $4.0 \pm 2.0$ & $3.6 \pm 1.0$ \\
\hline 9 & $15.8 \pm 1.4$ & $14.2 \pm 1.8$ & $13.0 \pm 2.0$ & $12.0+2.0$ & $11.2 \pm 2.6$ & $11.2 \pm 2.6$ \\
\hline$[0$ & $20.2 \pm 2.2$ & $19.6+3.0$ & $19.6 \pm 1.8$ & - & - & - \\
\hline
\end{tabular}

- = polyps retracted. 

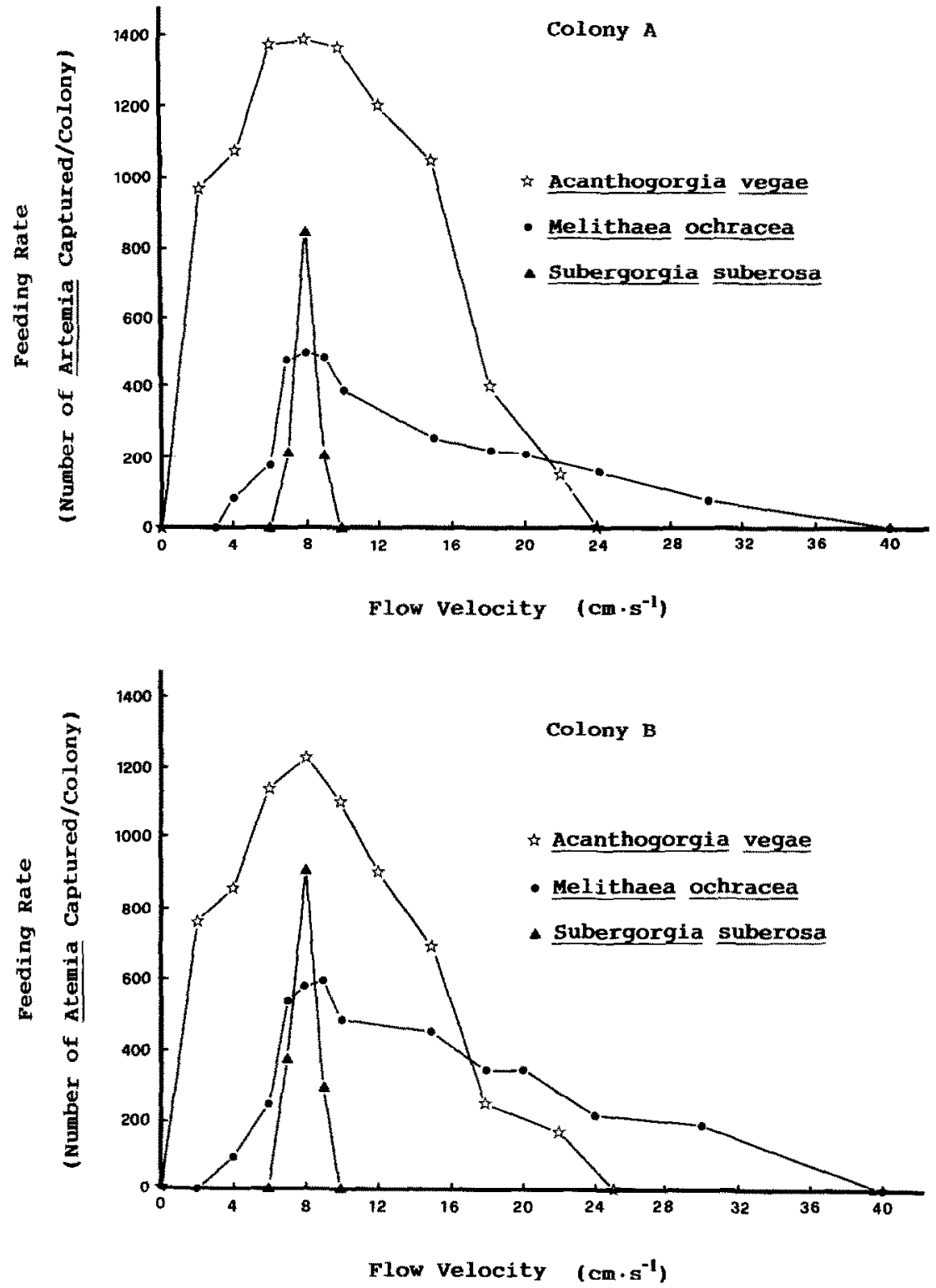

Fig. 1. Feeding rates (number of Artemia captured per colony) during the first hour of exposure to Artemia nauplii of the three gorgonians (Subergorgia suberosa; Acanthogorgia vegae; Melithaea ochracea) in a range of flow velocities.

To detect the natural mortality and precipitation of Artemia during the experiment, blank tests were conducted at the flow velocities of 8 and $40 \mathrm{~cm} \cdot \mathrm{s}^{-1}$ under the condition that no coral colony was introduced to the tank. 


\section{RESULTS}

\section{MORPHOMETRICS}

Morphometric data of the two colonies of the three gorgonian species are shown in Table I. Among the three species studied, S. suberosa has the largest polyps and the lowest polyp density. $M$. ochracea has the smallest polyps and the highest polyp density. Polyp size and polyp density of $A$. vegae were intermediate among the three species. The projected area of the three species were: $A$. vegae $>M$. ochracea $>$ S. suberosa.

\section{FEEDING EXPERIMENTS}

The results of the blank test showed that there was no significant change in number of Artemia nauplii during the $6 \mathrm{~h}$ experimental period. The regression slope was not

TABLE III

Residual concentration (shrimps $\cdot 1^{1}$ ) of Artemia nauplit (mean \pm I SD) in a range of flow velocitics in the 6-h period of feeding experiment for Acanthogorgia vegae. Initial concentration was $20 \mathrm{shrimps} \cdot 1^{-1}$.

\begin{tabular}{|c|c|c|c|c|c|c|}
\hline \multirow{3}{*}{$\begin{array}{l}\text { Flow velocity } \\
\qquad(\mathrm{cm} \cdot \mathrm{s}-1)\end{array}$} & \multicolumn{5}{|c|}{ Colony A } & \multirow[b]{3}{*}{6} \\
\hline & \multicolumn{5}{|c|}{ Time $(h)$} & \\
\hline & 1 & 2 & 3 & 4 & 5 & \\
\hline 2 & $7.2 \pm 1.0$ & $2.7+0.4$ & $0.8+0.2$ & $0.4+0.2$ & $0.2+0.1$ & $0.2+0.1$ \\
\hline 4 & $5.0 \pm 0.8$ & $1.5 \pm 0.5$ & $0.4 \pm 0.1$ & $0.2 \pm 0.0$ & $0.1 \pm 0.0$ & $0.1 \pm 0.0$ \\
\hline 6 & $0.3 \pm 0.0$ & $0.0 \pm 0.0$ & $0.0 \pm 0.0$ & $0.0 \pm 0.0$ & $0.0 \pm 0.0$ & $0.0 \pm 0.0$ \\
\hline 8 & $0.0 \pm 0.0$ & $0.0+0.0$ & $0.0 \pm 0.0$ & $0.0 \pm 0.0$ & $0.0+0.0$ & $0.0 \pm 0.0$ \\
\hline 10 & $0.6 \pm 0.1$ & $0.0 \pm 0.0$ & $0.0 \pm 0.0$ & $0.0 \pm 0.0$ & $0.0 \pm 0.0$ & $0.0+0.0$ \\
\hline 12 & $2.7 \pm 0.4$ & $0.6 \pm 0.1$ & $0.1+0.0$ & $0.0 \pm 0.0$ & $0.0 \pm 0.0$ & $0.0 \pm 0.0$ \\
\hline 15 & $7.2 \pm 1.1$ & $2.6 \pm 0.4$ & $1.0+0.2$ & $0.4+0.1$ & $0.2 \pm 0.1$ & $0.2 \pm 0.1$ \\
\hline 18 & $14.3 \pm 1.2$ & $10.3 \pm 0.3$ & $7.1 \pm 0.9$ & $5.9 \pm 1.0$ & $5.0 \pm 0.9$ & $3.9 \pm 0.7$ \\
\hline 22 & $17.0 \pm 1.7$ & $17.0 \pm 1.7$ & $13.1 \pm 1.2$ & $11.7 \pm 0.6$ & $10.7 \pm 1.3$ & $10.5 \pm 1.0$ \\
\hline
\end{tabular}

\section{Colony B}

\begin{tabular}{rrrrrrr}
3 & $9.0 \pm 2.8$ & $6.0 \pm 1.2$ & $4.6 \pm 1.8$ & $4.0 \pm 2.0$ & $3.6 \pm 0.6$ & $2.4 \pm 0.2$ \\
4 & $7.6 \pm 2.6$ & $5.8 \pm 1.8$ & $3.4 \pm 1.0$ & $2.8 \pm 0.6$ & $2.6 \pm 0.6$ & $2.0 \pm 0.8$ \\
6 & $3.6 \pm 1.0$ & $2.2 \pm 0.6$ & $2.6 \pm 0.6$ & $2.2 \pm 0.6$ & $2.0 \pm 0.8$ & $1.4 \pm 0.6$ \\
8 & $2.4 \pm 0.6$ & $1.6 \pm 1.0$ & $1.0 \pm 0.8$ & $1.6 \pm 0.4$ & $0.6 \pm 0.6$ & $0.2 \pm 0.2$ \\
10 & $4.2 \pm 0.6$ & $2.8 \pm 1.4$ & $2.6 \pm 1.0$ & $2.0 \pm 0.4$ & $2.0 \pm 0.4$ & $1.4 \pm 0.6$ \\
12 & $7.0 \pm 1.2$ & $5.6 \pm 2.2$ & $4.8 \pm 0.6$ & $3.8 \pm 1.4$ & $2.8 \pm 0.6$ & $2.0 \pm 0.8$ \\
15 & $10.0 \pm 2.0$ & $5.8 \pm 0.6$ & $3.2 \pm 0.6$ & $2.8 \pm 0.6$ & $2.6 \pm 1.0$ & $2.4 \pm 0.2$ \\
18 & $16.4 \pm 1.0$ & $13.0 \pm 2.8$ & $11.2 \pm 1.8$ & $100 \pm 0.8$ & $9.2 \pm 1.8$ & $9.2 \pm 0.6$ \\
22 & $17.6 \pm 1.0$ & $16.4 \pm 1.0$ & $16.0 \pm 2.0$ & $14.4 \pm 1.0$ & $12.8 \pm 1.4$ & $10.6 \pm 0.6$ \\
\hline
\end{tabular}


significantly different than $0\left(t=0.57, n=35, p>0.05\right.$, at $8 \mathrm{~cm} \cdot \mathrm{s}^{-1} ; t=0.32, n=35$, $p>0.05$, at $40 \mathrm{~cm} \cdot \mathrm{s}^{-1}$ ), so natural mortality and precipitation of Artemia shrimps during the experiment period can be neglected.

Colonies of $S$. suberosa expand their polyps at flow velocities from 5 to $10 \mathrm{~cm} \cdot \mathrm{s}^{-1}$, but the feeding appear to occur between 7 and $9 \mathrm{~cm} \cdot \mathrm{s}^{-1}$ (Table II). A slight difference was found between the two colonies tested. Only some polyps of colony A were expanded at flow velocities of 5 and $6 \mathrm{~cm} \cdot \mathrm{s}^{-1}$, but the coral withdrew its polyps after exposure to Artemia for $5 \mathrm{~h}$ at $5 \mathrm{~cm} \cdot \mathrm{s}^{-1}$. Polyps of colony B were not expanded at $5 \mathrm{~cm} \cdot \mathrm{s}^{-1}$. Feeding was not detectable at 5 and $6 \mathrm{~cm} \cdot \mathrm{s}^{-1}$ for both colonies. At 7,8 , and $9 \mathrm{~cm} \cdot \mathrm{s}^{-1}$, most of the polyps were fully expanded and feeding was detected. Feeding

TABLE IV

Residual concentration (shrimps $\cdot 1^{-1}$ ) of Artemia nauplii (mean $\pm 1 \mathrm{SD}$ ) in a range of flow velocities in the 6-h period of feeding experiment for Melithaea ochracea. Initial concentration was 20 shrimps $\cdot 1^{-1}$.

\begin{tabular}{|c|c|c|c|c|c|c|}
\hline \multicolumn{7}{|c|}{ Colony A } \\
\hline \multirow{2}{*}{$\begin{array}{c}\text { Flow velocity } \\
\left(\mathrm{cm} \cdot \mathrm{s}^{-1}\right)\end{array}$} & \multicolumn{6}{|c|}{ Time (h) } \\
\hline & 1 & 2 & 3 & 4 & 5 & 6 \\
\hline 4 & $18.8 \pm 1.3$ & $17.4 \pm 1.5$ & $17.4 \pm 2.6$ & $16.4 \pm 1.9$ & $14.2 \pm 2.3$ & $14.0 \pm 2.1$ \\
\hline 6 & $16.8 \pm 3.1$ & $16.4 \pm 2.2$ & $15.4 \pm 1.4$ & $12.8 \pm 1.3$ & $12.4 \pm 2.7$ & $12.0 \pm 1.4$ \\
\hline 7 & $12.8 \pm 1.6$ & $12.6 \pm 1.9$ & $12.0 \pm 1.7$ & $11.8 \pm 1.6$ & $11.6 \pm 1.6$ & $11.2 \pm 1.7$ \\
\hline 8 & $12.4 \pm 0.8$ & $11.8 \pm 1.3$ & $11.4 \pm 1.0$ & $10.8 \pm 1.3$ & $10.2 \pm 1.2$ & $10.2 \pm 1.0$ \\
\hline 9 & $12.8 \pm 1.0$ & $12.2 \pm 1.5$ & $11.8 \pm 1.8$ & $11.6 \pm 1.4$ & $11.2 \pm 1.2$ & $11.0 \pm 1.2$ \\
\hline 10 & $13.8 \pm 1.2$ & $13.4 \pm 1.8$ & $12.8 \pm 1.6$ & $12.2 \pm 1.7$ & $11.6 \pm 1.9$ & $11.4 \pm 2.0$ \\
\hline 15 & $14.2 \pm 1.7$ & $14.2 \pm 3.5$ & $13.8 \pm 3.0$ & $13.2 \pm 2.6$ & $13.0 \pm 1.9$ & $12.8 \pm 2.1$ \\
\hline 18 & $15.8 \pm 1.9$ & $14.6 \pm 1.0$ & $14.2 \pm 1.8$ & $13.6 \pm 2.2$ & $12.6 \pm 1.9$ & $11.8 \pm 2.0$ \\
\hline 20 & $16.4 \pm 2.1$ & $16.2 \pm 2.3$ & $13.6 \pm 2.3$ & $12.2 \pm 0.4$ & $11.6 \pm 1.9$ & $11.2 \pm 2.9$ \\
\hline 24 & $18.2 \pm 1.6$ & $15.2 \pm 1.9$ & $15.4 \pm 2.2$ & $14.2 \pm 0.7$ & $12.2 \pm 1.2$ & $11.8 \pm 1.6$ \\
\hline 30 & $18.8 \pm 1.1$ & $18.0 \pm 1.1$ & $17.6 \pm 1.0$ & $17.4 \pm 1.0$ & $16.0 \pm 2.1$ & $15.8 \pm 1.9$ \\
\hline 40 & $20.0 \pm 1.7$ & $20.2 \pm 1.6$ & $21.4 \pm 1.6$ & $19.8 \pm 1.7$ & $20.0 \pm 1.8$ & $19.8 \pm 1.7$ \\
\hline
\end{tabular}

Colony B

\begin{tabular}{rrrrrrr}
\hline 4 & $18.6 \pm 1.0$ & $18.6 \pm 1.0$ & $17.2 \pm 1.0$ & $16.0 \pm 2.0$ & $15.4 \pm 1.4$ & $14.0 \pm 2.0$ \\
6 & $16.4 \pm 3.4$ & $14.6 \pm 2.6$ & $13.0 \pm 3.2$ & $12.2 \pm 3.0$ & $12.0 \pm 2.0$ & $12.2 \pm 4.2$ \\
7 & $12.2 \pm 2.2$ & $12.4 \pm 4.2$ & $11.0 \pm 3.2$ & $11.0 \pm 3.6$ & $10.2 \pm 1.8$ & $11.0 \pm 0.8$ \\
8 & $11.6 \pm 1.8$ & $9.6 \pm 1.8$ & $9.0 \pm 1.6$ & $8.4 \pm 1.8$ & $8.0 \pm 2.8$ & $6.8 \pm 1.4$ \\
9 & $11.4 \pm 2.2$ & $9.4 \pm 1.0$ & $9.6 \pm 0.2$ & $8.6 \pm 1.8$ & $8.6 \pm 1.0$ & $7.4 \pm 1.0$ \\
10 & $13.0 \pm 1.2$ & $13.2 \pm 2.2$ & $11.4 \pm 3.4$ & $10.6 \pm 1.0$ & $10.4 \pm 1.9$ & $10.4 \pm 2.2$ \\
15 & $13.4 \pm 2.6$ & $11.0 \pm 3.2$ & $10.8 \pm 1.8$ & $9.4 \pm 1.0$ & $9.2 \pm 1.4$ & $8.8 \pm 3.8$ \\
18 & $15.0 \pm 0.8$ & $13.4 \pm 3.4$ & $12.4 \pm 4.2$ & $12.4 \pm 2.6$ & $11.8 \pm 3.0$ & $12.0 \pm 3.6$ \\
20 & $15.0 \pm 2.8$ & $14.0 \pm 1.6$ & $12.8 \pm 3.0$ & $12.8 \pm 1.4$ & $11.8 \pm 1.8$ & $11.2 \pm 2.2$ \\
24 & $17.0 \pm 1.2$ & $16.0 \pm 2.0$ & $15.8 \pm 3.8$ & $14.4 \pm 2.2$ & $12.4 \pm 2.6$ & $11.8 \pm 2.6$ \\
30 & $17.2 \pm 1.8$ & $16.4 \pm 2.2$ & $15.6 \pm 2.2$ & $16.2 \pm 3.0$ & $15.0 \pm 2.0$ & $13.0 \pm 2.8$ \\
40 & $19.6 \pm 2.6$ & $19.4 \pm 1.0$ & $19.6 \pm 2.2$ & $19.4 \pm 2.2$ & $19.4 \pm 1.8$ & $19.8 \pm 2.6$ \\
\hline
\end{tabular}


rates at $8 \mathrm{~cm} \cdot \mathrm{s}^{-1}$ were the highest (Fig. I). At $10 \mathrm{~cm} \cdot \mathrm{s}^{-1}$, the coral colonies expanded their polyps in the beginning, but feeding was not detectable. The colonies gradually withdrew their polyps after $3 \mathrm{~h}$ of exposure to Artemica.

Both colonies of $A$. vegae expanded their polyps at flow velocities from $\theta$ to $24 \mathrm{~cm} \cdot \mathrm{s}^{-1}$ and feeding could be detected at velocities between 2 and $22 \mathrm{~cm}^{\cdot} \mathrm{s}^{-1}$ (Table III). The highest feeding rates occurred at $6-10 \mathrm{~cm} \cdot \mathrm{s}^{-1}$ (Fig. 1).

Both colonies of $M$. ochracea expanded their polyps at flow velocities from 4 to $50 \mathrm{~cm} \cdot \mathrm{s}^{-1}$ and feeding was detected between 4 and $40 \mathrm{~cm} \cdot \mathrm{s}^{-1}$ (Table IV). At flow velocities between 40 and $50 \mathrm{~cm} \cdot \mathrm{s}^{-1}$, the coral polyps were fully expanded but no feeding effect was detectable.

Feeding rates at different flow velocities showed that the highest rate of the three species appeared at $\approx 8 \mathrm{~cm} \cdot \mathrm{s}^{-1}$ (Fig. 1). At $8 \mathrm{~cm} \cdot \mathrm{s}^{-1}$, feeding rates of the three species is ranked $A$. vegae $>S$. suberosa $>M$. ochracea. However, both the normalized colony feeding effectiveness (Fig. 2) and the polyp feeding effectiveness (Fig. 3) at $8 \mathrm{~cm} \cdot \mathrm{s}^{\cdots 1}$ are ranked $S$. suberosa $>A$, vegae $>M$, ochracea.

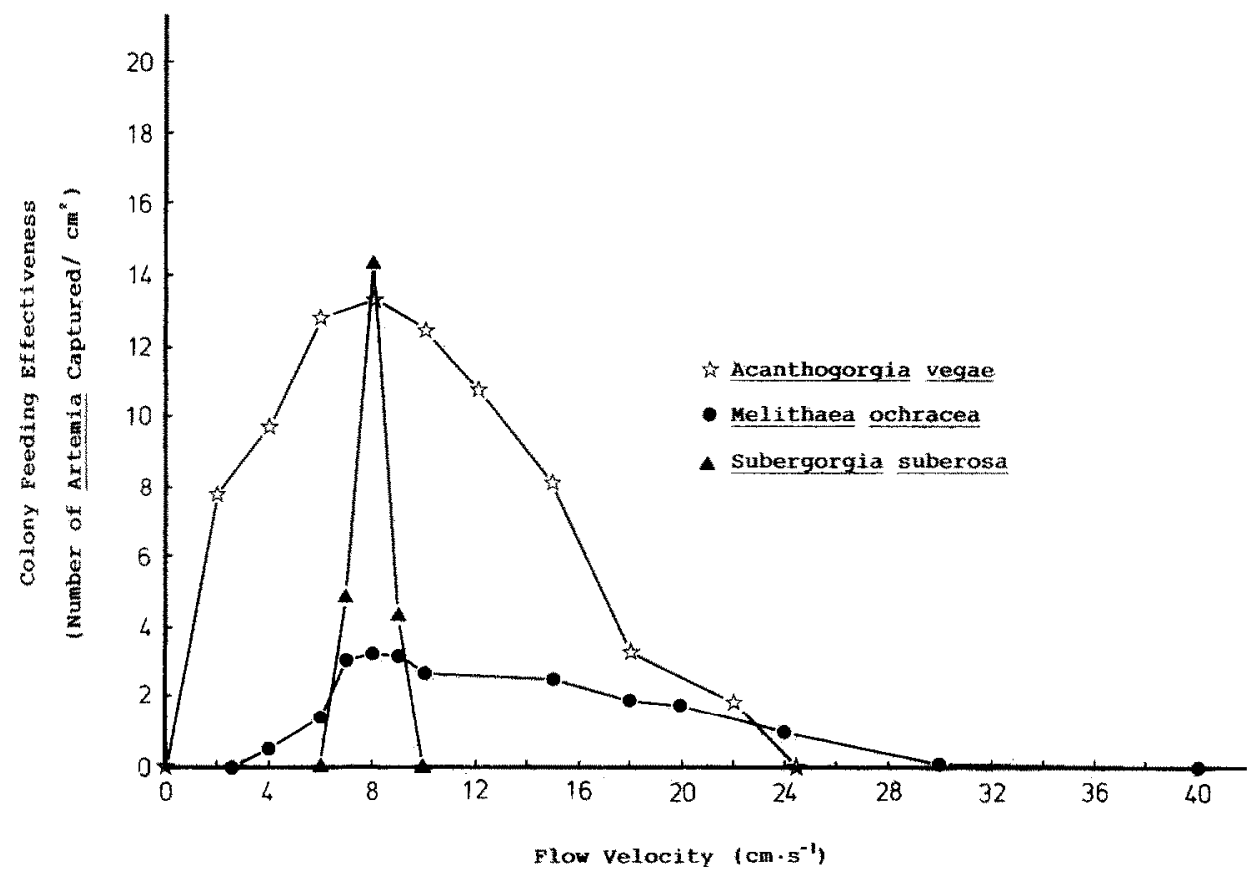

Fig. 2. Normalized colony feeding effectiveness (number of Artemia captured per $\mathrm{cm}^{2}$ ) for the three gorgonians (Subergorgla suberosa, Acanthogorgia vegaz; wehthaea thraca) in a range of how velocities duing the first hour of exposure to Artemin naupli.. 


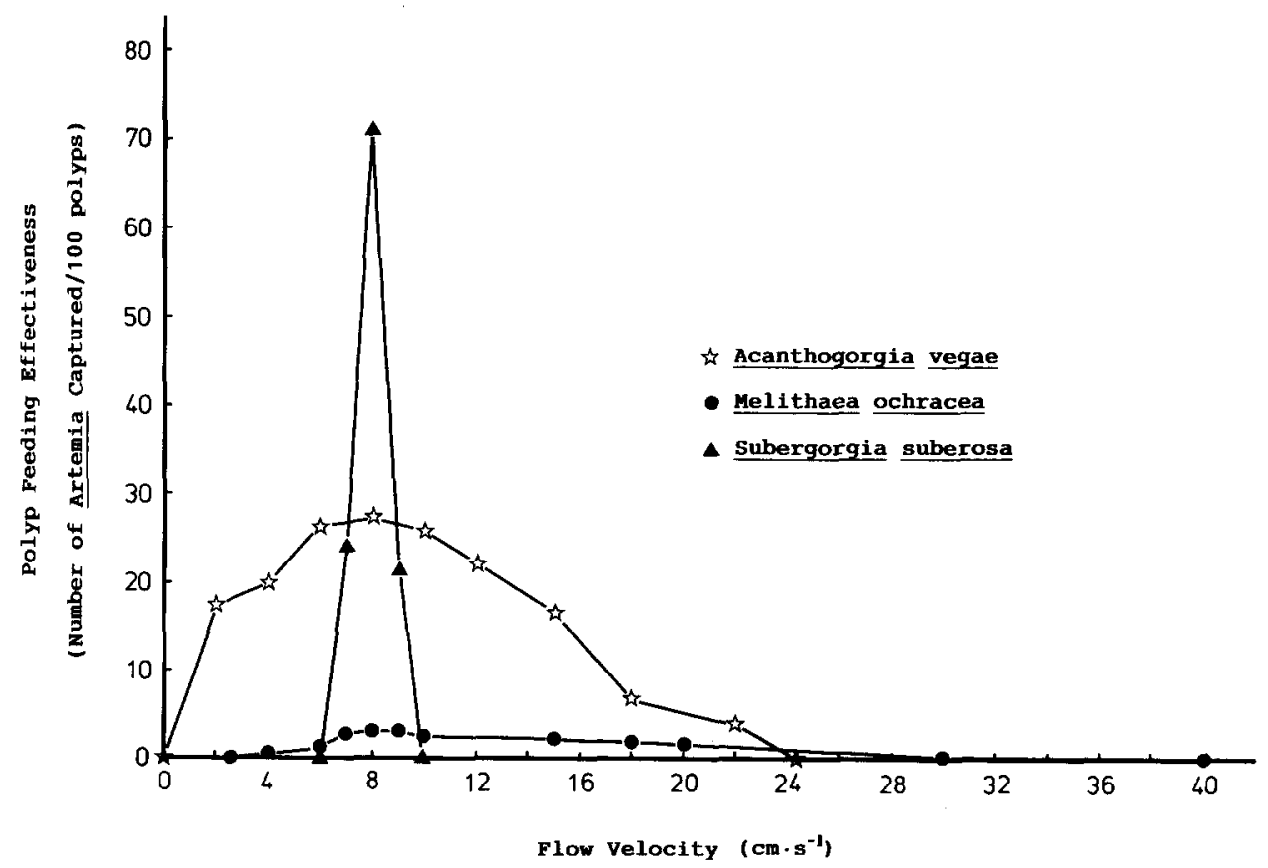

Fig. 3. Normalized polyp feeding effectiveness (number of Artemia captured per 100 polyps) for three gorgonians (Subergorgia suberosa; Acanthogorgia vegae; Melithaea ochracea) in a range of flow velocities during the first hour of exposure to Artemia nauplii.

\section{Discussion}

Feeding rates of the three species in different flow velocities show a similar trend (Fig. 1). Feeding rates increased initially with flow velocity, reached a peak value at $\approx 8 \mathrm{~cm} \cdot \mathrm{s}^{-1}$, then decreased with increasing flow velocities. A similar phenomenon was noted in a sea pen (Best, 1988) and two gorgonians (Sponaugle \& LaBarbera, 1991). Sponaugle (1991) suggested that the enhanced feeding success at intermediate flow velocities is typical of some suspension feeders. Feeding rates of a suspension feeder at different flow velocities are determined by the combination of three factors: (1) capture efficiency, (2) rate of encounter with particles, and (3) deformation of the feeding elements (Leonard et al., 1988). Since gorgonians are passive suspension feeders, they must contend with potentially damaging hydrodynamic drag forces while filtering the water for food (Lewis, 1982; Patterson, 1984). In slow currents, volume of flow increases with flow velocity and the encounter rate increases (Best, 1988). Up to a point, the high encounter rate compensates for declines in capture efficiency as the feeding elements deform. Beyond this point, food capturing function becomes more impaired and feeding rate decreases. At very high flow velocity, organisms quit feeding and take evasive action by retracting polyps. 
Each of the three gorgonians expanded their polyps and fed in a particular range of flow velocities. The lower velocity limit is likely constrained by feeding success, while the upper velocity limit may be constrained by either feeding success or the probability of detachment (Wainwright \& Koehl, 1976; Harvell \& LaBarbera, 1984). The range of flow velocities in which a gorgonian coral expands its polyps can also be viewed as a balance between the energy gained from feeding and the cost of keeping the polyps expanded. When water movement is too low, it may be more costly for the colony to remain expanded and capturing few zooplankton than to contract and capture none (Sebens, 1984). When currents are too strong to allow efficient feeding and the energy cost of remaining expanded is so high, then colonies may retract their polyps. Thus, at both low and high flow velocities, colonies expanded their polyps initially but then retracted them after a few hours of exposure to food items. The energy cost for a coral colony to remain expanded is related to polyp morphology. A tall polyp not only receives greater drag but also is more easily deformed under strong currents (Koehl, 1977). Best (1988) demonstrated that the deformability of organisms strongly affects fceding efficiency and volume of water filtered. Although the branches of the three gorgonians have not been observed to bend in any current (Muzik \& Wainwright, 1977; this study), deformation of polyps in high flow velocities was evident (Fig. 4). Among the three species studied, $S$. suberosa has the tallest polyps and is more casily deformed at high flow velocities. At $8 \mathrm{~cm} \cdot \mathrm{s}^{-1}$, polyp deformation of $S$. suberosa was noticeable and the polyps could still feed in downstream eddies. Downstrean eddies may result in localized concentrations of prey and the reduced currents in eddies may allow more

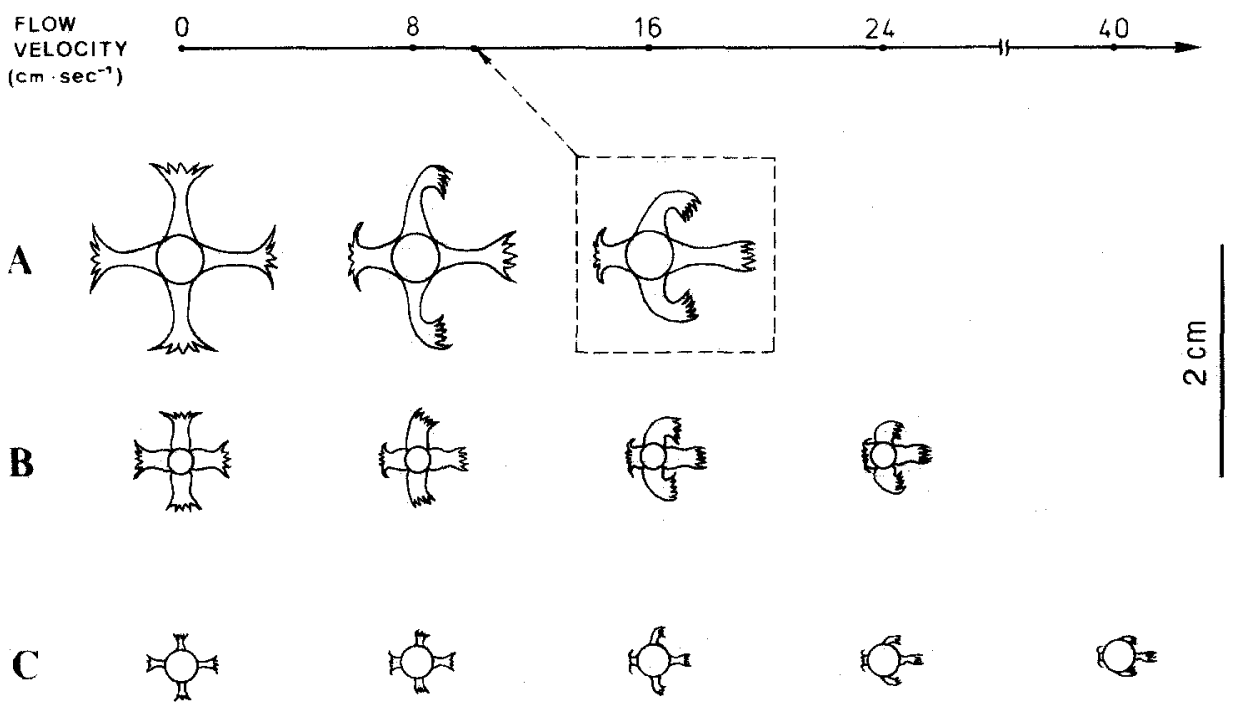

Fig. 4. Deformation of polyps of three gorgonians (Subergorgia suberosa; Acanhogorgia vegae; Melithaea ochracea) at different flow velocities. Pictures are redrawn to scale from microscopic photographs. 
efficient feeding (Leversee, 1976). But at $10 \mathrm{~cm} \cdot \mathrm{s}^{-1}$, polyps are so severely deformed that they can no longer feed effectively. Because the energy cost of keeping the polyps expanded is so high, the coral contracts its polyps after several hours of exposure to such flow velocity. On the other hand, polyps of $M$. ochracea are the shortest and the least easily deformed at high flow velocities. In addition, polyps of $M$. ochracea are arranged semi-laterally on the surface of the branches and expanded directly into the downstream zone of reduced currents (Muzik \& Wainwright, 1977). These features enable $M$. ochracea to feed in a wide range of flow velocities. Although $S$. suberosa feed in a much narrower range of flow velocities, its feeding effectiveness per unit surface area and per polyp are the highest in the optimal flow velocity (Figs 2 and 3 ).

The feeding abilities of the three gorgonian species reflect the differences in their morphologies and habitats. The currents in the coastal areas of southern Taiwan are mostly dominated by semidiurnal tides. In Nanwan Bay, where the gorgonians were collected, the tidal currents flow westward during flood tide and eastward during ebb tide (Dai, 1991). Current velocities range from 2 to $50 \mathrm{~cm} \cdot \mathrm{s}^{-1}$ with an average of $15 \mathrm{~cm} \cdot \mathrm{s}^{-1}$. Current velocity is stronger in shallow water at depths between 5 and $15 \mathrm{~m}$, especially in exposed areas (Liang et al., 1978). M. ochracea, which can feed in a wide range of flow velocities, is widely distributed on the reefs of southern Taiwan (Chen \& Chang, 1991). Colonies of $M$. ochracea often grow on the upper part of reef front where currents are relatively strong. This distribution pattern is consistent with its ability to feed in relatively high flow velocities. $S$. suberosa, which feeds in a relatively narrow range of flow velocities, has restricted distribution on the reefs of southern Taiwan. If often exists on the lower part of reef slopes or on sheltered boulders scattered over sandy bottom at depths between 15 and $25 \mathrm{~m}$. A. vegae, which feed in relatively strong currents, usually grow on semi-exposed reef fronts or the lateral side of boulders.

This study reveals that different gorgonacean corals may feed most successfully in different ranges of flow velocities. Such flow-related feeding capabilities of suspension feeders are likely related to the deformation of their feeding elements in different flow velocities. The feeding performances of passive suspension feeders in different ranges of flow velocities may have significant influences on their distribution in the environment, particularly where flow regimes are more complex such as on coral reefs.

\section{ACKNOWLEDGEMENTS}

We wish to express our appreciation to Drs. K.Y. Wei, T.-S. Chiu and C.-P. Chen for their comments on the manuscript. We also thank Mr. Y.-C. Tsay and T.-Y. Fan for their assistance in specimen collection. This study was supported by a grant from the National Science Council, R.O.C. (NSC 79-0418-B-002A-15). 


\section{REFERENCES}

Bayer, F.H., 1981. Key to genera of Octocorallia exclusive of Pennatulacea (Coelenterata: Anthozoa), with diagnosis of new taxa. Proc. Biol. Soc. Wash., Vol, 94, pp. 902-947.

Best, B. A., 1988. Passive suspension feeding in a sea pen: effects of ambient flow on volume flow rate and filtering efficiency. Biol. Bull., Vol. 175, pp. 332-342.

Chen, C.C. \& K. H. Chang, 1991. Gorgonacea (Coelenterata: Anthozoa: Oetocorallia) of southern Taiwan. Bull. Inst. Zool. Acad. Sinica, Vol. 30, pp. 149-182.

Dai, C.F., 1991. Reef environment and coral fauna of southern Taiwan. Atoll Res. Bull., Vol 354, pp. 124.

Grigg, R., 1972. Orientation and growth form of sea fans. Limnol. Oceanogr., Vol. 17, pp. 85-192.

Harvell, D. \& M. LaBarbera, 1985. Flexibility: a mechanism for control of local velocity in hydroid colonies. Biol. Bull., Vol. 168, pp. 312-320.

Hunter, T., 1989. Suspension feeding in oscillating flow: the effect of colony morphology and flow regime on plankton capture by the hydroid Obelia longissima. Biol. Bull.. Vol. 176, pp. 41-49.

Jørgensen, C.B., 1955. Quantitative aspects of filter feeding in invertebrates. Biol. Rev, Vol. 30, pp. 391454.

Kochl, M.A. R., 1977. Effects of sea anemones on the flow fores they encounter. J. Exp. Biol. Vol. 69 , pp. 87-105.

Lasker, H. R., 1981. A comparison of the particulate feeding abilities of three species of gorgonian soft coral. Mar. Ecol. Prog. Ser., Vol. 5, pp. 61-67.

Lasker, H.R., M.D. Gottfried \& M.A. Coffroth, 1983. Effects of depth on the feeding eapabilities of two octocorals. Mar. Biol., Vol. 73, pp. 73-78.

Leonard, A.B., J.R. Strickler \& N.D. Holland, 1988. Effects of current speed on filtration during suspension feeding in Oligometra serripinna (Echinodermata: Crinoidea). Mar. Biol., Vol. 97, pp. 111-125.

Leversee, G. J., 1976. Flow and feeding in fan-shaped colonies of the gorgonian coral, Leptogorgia. Biol. Bull. . Vol. 151, pp. 344-356.

L.wis, J. B., 1982. Feeding behaviour and feeding ecology of the Octocorallia (Coelenterata: Anthozoa). $J$. Zool., Lond., Vol. 196, pp. 371-384.

Lang. N. K., S.L. Lien, W.C. Chen and H.T. Chang. 1978. Occanographic investigation th the vicinity of Maansan-Nanwan Bay. Spec. publ. No. 18, Institute of Oceanography, National Taiwan University, Taipei, Taiwan, 207 pp.

Muzik, K. \& S. Wainwright, 1977. Morphology and habitat of five Fijian sea fans. Bull. Mar. Sci., Vol. 27, pp. $308-337$.

Okamura, B., 1990. Particle size, flow velocity, and suspension-feeding by the erect bryozoans Bugula neritina and B. stolonifera. Mar. Biol., Vol. 105, pp. 33-38.

Patterson, M.R., 1984. Patterns of whole colony prey capture in the octocoral, Algymium siderium. Biol. Bull.. Vol. 167, pp. 613-629.

Pauterson, M.R., 1991. The effects of flow on polyp-level prey capture in an octocoral. Alegrium siderium. Biol. Bull. Vol. 180, pp. 93-102.

Riedl, R., 1971. Water movement. In, Marine ecotogy, edited by O. Kinne, Wiley-Interscience, London. pp. $1123-1150$.

Scbens, K.P., 1984. Water llow and coral colony sise: interhabiat comparisons of the octecural $A$ kleyonim siderium. Proc. Natl. Acad. Sci. USA, Vol. 81, pp. 5473-5477.

Sponaugle, S., 1991. Flow patterns and velocities around a suspension-fceding gorgonian polyp: evidence from physical models. J. Exp. Mar. Biol. Ecol., Vol. 148, pp. 135-145.

Sponaugle, S. \& M. LaBarbera, 1991. Drag-induced deformation: a functional feeding strategy in two species of gorgonians. J. Exp. Mar. Biol. Ecol.. Vol. 148, pp. 121-134.

Wainwright, S. A. \& J. R. Dillon, 1969. On the oricntation of sea fans (Genus Giugemia). Bisl. Butl., Vol. 136, pp. 130-139. 
Wainwright, S.A.\& M.A.R. Koehl, 1976. The nature of flow and the reaction of benthic enidaria to it. In, Coelenterate ecology and behavior, edited by G.O. Mackie, Plenum Press, New York, pp. 5-21.

Wainwright, S.A., W.D. Biggs, J.D. Currey \& J. M. Gosline, 1976. Mechanical design in organisms. Princeton University Press, Princeton, New Jersey, USA, $423 \mathrm{pp}$.

Zou, R. L. \& P.J.B. Scott, 1980. The Gorgonacea of Hong Kong. In, The marine flora and fauna of Hong Kong and Southem China Sea, Vol. 1, edited by B.S. Morton \& C. K. Tseng, Hong Kong University Press, Hong Kong, pp. 135-159. 